\title{
HUBUNGAN TINGGI BADAN DENGAN PANJANG TULANG FEMUR PADA ETNIS SANGIHE DI MADIDIR URE
}

\author{
Novitasari Mangayun \\ George. N. Tanudjaja \\ Taufiq Pasiak
}

\author{
Bagian Anatomi - Histologi Fakultas Kedokteran Universitas Samratulangi \\ Email: Novitamangayun@yahoo.com
}

\begin{abstract}
Identification is one of the most important examinations to determine somebody's identity. Body length estimation is one of the parameter in forensic anthropology and helps establish a person's biological profile. Body length can be estimated by long bones measurement, including femur. The objective of this study is to determine the correlation of body length and femur length on adult Sangihe in Madidir Ure. This study is an analytical descriptive using cross-sectional design. This study was conducted in Madidir Ure with a total of 94 subjects consisting of 56 males and 38 females. The samples were chosen with purposive sampling method and analysed with Pearson correlation and simple linear regression. The result showed strong correlation between body length and femur length, with value of (r) 0537 in total subjects, 0,658 in males and 0,650 in females. Equations that were made from the result of simple linear regression are, Body length $=104,662+$ $1,740 \mathrm{x}$ femur length for males, body length $=104,298+1,410 \mathrm{x}$ femur length for females and body length $=97,265+1,824 \times$ femur length in total subjects.
\end{abstract}

Keyword : Identification, body length, femur length, etnis Sangihe, Madidir Ure.

Abstrak: Identifikasi ialah pemeriksaan penting dalam menentukan kejelasan identitas seseorang. Pengukuran tinggi badan merupakan suatu parameter antropologi forensik dan membantu dalam membangun profil biologis seseorang. Tinggi badan dapat ditentukan dengan tulang panjang, termasuk tulang femur.Peneltian ini bertujuan untuk menentukan hubungan panjang badan dengan panjang tulang femur pada Etnis Sangihe di Madidir Ure. Penelitian ini merupakan penelitin deskriptif analitik dengan rancangan cross-sectional, penelitian ini dilakukan di Madidir Ure dengan sampel berjumlah 94 orang yang terdiri dari 56 orang laki-laki dan 38 orang perempuan. Sampel diambil dengan cara purposive sampling dan dianalisis dengan korelasi pearson serta analisis regresi linier sederhana, dan didapatkan hubungan yang kuat antara panjang badan dengan panjang tulang femur dengan koefisien korelasi (r) keseluruhan adalah 0,537, pada laki-laki 0,658 dan pada perempuan 0,650. Dari hasil analisis regresi linier sederhana didapatkan rumus PB laki-laki = 104,662 $+1,740 \mathrm{x}$ panjang femur, PB perempuan $=104,298+1,410 \mathrm{x}$ panjang femur dan secara keseluruhan $\mathrm{PB}=97,265+1,824 \times$ panjang femur.

Kata kunci: Identifikasi, Tinggi badan, panjang femur, etnis sangihe, madidir ure. 
Tubuh manusia mempunyai perbedaan tertentu antara panjang bagian tubuh yang satu dengan yang lainnya.Seluruh deskripsi tubuh manusia didasarkan pada posisi anatomis yaitu seseorang berdiri tegak,ekstrenitas superior berada di samping tubuh, dan wajah serta telapak tangan menghadap ke depan. ${ }^{1}$ Anatomi manusia telah melalui berbagai macam perkembangan dan bersama-sama dengan cabang ilmu kedokteran lainnya menimbulkan ilmu terapan, salah satunya adalah antropologi ragawi. Teknik antropologi ragawi dapat digunakan untuk memperkirakan umur,jenis kelamin,ukuran bagian-bagian badan manusia, dan jenis ras berdasarkan kerangka seseorang. Teknik ini juga dapat digunakan dalam proses identifikasi yang merupakan bidang telaah kedokteran forensic. $^{2}$

Identifikasi sangatlah penting pada orang yang telah meninggal, untuk kepastian atau kejelasan identitas seseorang.Proses identifikasi akan menjadi sulit apabila mayat yang dikirim ke rumah sakit atau puskesmas telah mengalami pembusukan atau mengalami kerusakan berat baik akibat kebakaran, ledakan, kecelakaan pesawat, ataupun tinggal sebagian jaringan tubuh misalnya pada kasus mutilasi (tubuh terpotong-potong). Pada jenazah yang tidak utuh lagi (terpotongpotong), perkiraan panjang jenazah dapat dilakukan dengan mengukur bagian tertentu tubuh jenazah untuk memperkirakan tinggi badan pada saat masih hidup. ${ }^{3}$

Penelitian mengenai hubungan panjang tulang-tulang panjang dengan tinggi badan sudah pernah dilakukan di Fakultas Kedokteran Unsrat, namun dalam penelitian yang sudah dilakukan, belum ada yang meneliti terhadap suku atau etnis tertentu.Oleh sebab itu penulis terdorong untuk melakukan penelitian mengenai hubungan panjang badan dengan panjang tulang femur pada etnis Sangihe di Madidir Ure.

\section{METODE PENELITIAN}

Jenis penelitian yang dilakukan adalah jenis penelitian analitik dengan rancangan cross-sectional (potong lintang). Penelitian ini dilakukan di kelurahan Madidir Ure di kota Bitung pada bulan November 2013. Sampel penelitian ini adalah seluruh penduduk kota bitung etnis Sangihe di kelurahan Madidir Ure dengan pemilihan menggunakan cara purposive sampling.

\section{Cara Pengukuran}

1. Panjang Badan

Subyek berdiri sempurna membelakangi dinding dalam posisi anatomi (telapak tangan menggantung pada sisi tubuh, kaki rapat, kepala, punggung, pantat dan tumit menyentuh dinding) pada lantai yang rata tanpa penutup kepala, alas kaki dan kepala menghadap ke depan. Subyek diminta menarik napas dalam-dalam dan pengukuran siambil dari puncak kepala (vertex) sampai tumit (os kalkaneus) dan dicatat dalam bentuk $\mathrm{cm} .{ }^{4}$

2. Panjang Femur

Subyek diminta berdiri atau tidur terlentang, lalu diukur panjang femur mulai dari trokanter mayor sampai kondilus lateralis.

\section{Analisis Data}

Setelah diperoleh data mengenai ukuran panjang badan dan panjang femur, kemudian dihitung nilai rata-rata dan simpangan baku dari umur, variable panjang badan dan panjang femur, kemudian dilakukan analisis korelasi dan regresi linier sederhana dengan rumus : ${ }^{5}$

$$
\begin{aligned}
& \mathrm{Y}=\mathrm{a}+\mathrm{bX} \\
& \mathrm{Y}=\text { Variabel terikat ( panjang badan) } \\
& \mathrm{X}=\text { Variabel bebas (panjang femur) } \\
& \mathrm{a}=\text { Nilai konstanta } \\
& \mathrm{b}=\text { Koefisien regresi }
\end{aligned}
$$

\section{HASIL PENELITIAN}

Penelitian ini dilakukan terhadap 94 orang etnis Sangihe di Madidir Ure dengan usia antara 21-55 tahun, yang terdiri dari 56 orang laki-laki dan 38 orang perempuan, yang dilakukan pada tanggal 23 November 2013. Hasilpenelitian ini sebagai berikut: 
Tabel 1. Umur subyek penelitian

\begin{tabular}{l|l|l|l|l}
\hline Jenis Kelamin & Jumlah & Umur(tahun) & $\begin{array}{l}\text { Rata-Rata } \\
\text { (tahun) }\end{array}$ & $\begin{array}{l}\text { Simpangan } \\
\text { Baku (tahun) }\end{array}$ \\
\hline Laki-laki & 56 & $25-54$ & 41,16 & 6,830 \\
Perempuan & 38 & $23-55$ & 38,82 & 8,589 \\
Keseluruhan & 94 & $23-55$ & 40,21 & 7,634 \\
\hline
\end{tabular}

Tabel 2. Panjang badan subjek penelitian

\begin{tabular}{c|c|c|c|c}
\hline $\begin{array}{c}\text { Jenis } \\
\text { Kelamin }\end{array}$ & Jumlah & $\begin{array}{c}\text { Panjang Badan } \\
(\mathrm{cm})\end{array}$ & $\begin{array}{c}\text { Rata-rata } \\
(\mathrm{cm})\end{array}$ & $\begin{array}{c}\text { Simpangan } \\
\text { Baku }(\mathrm{cm})\end{array}$ \\
\hline Laki-laki & 56 & $136,5-179,0$ & 163,302 & 6,4351 \\
Perempuan & 38 & $138,5-164,5$ & 151,076 & 5,8313 \\
Keseluruhan & 94 & $136,5-179,0$ & 158,360 & 8,6256 \\
\hline
\end{tabular}

Tabel 3. Panjang femur kanan subjek penelitian

\begin{tabular}{c|c|c|c|c}
\hline $\begin{array}{c}\text { Jenis } \\
\text { Kelamin }\end{array}$ & Jumlah & $\begin{array}{c}\text { Panjang femur } \\
\text { kanan }(\mathrm{cm})\end{array}$ & $\begin{array}{c}\text { Rata-rata } \\
(\mathrm{cm})\end{array}$ & $\begin{array}{c}\text { Simpangan } \\
\text { Baku }(\mathrm{cm})\end{array}$ \\
\hline Laki-laki & 56 & $29,1-41,0$ & 33,709 & 2,4347 \\
Perempuan & 38 & $28,1-37,5$ & 33,166 & 2,6866 \\
Keseluruhan & 94 & $28,1-41,0$ & 33,489 & 2,5395 \\
\hline
\end{tabular}

Tabel 4. Panjang femur kiri subjek penelitian

\begin{tabular}{c|c|c|c|c}
\hline $\begin{array}{c}\text { Jenis } \\
\text { Kelamin }\end{array}$ & Jumlah & $\begin{array}{c}\text { Panjang Femur } \\
\text { Kiri }(\mathrm{cm})\end{array}$ & $\begin{array}{c}\text { Rata-rata } \\
(\mathrm{cm})\end{array}$ & $\begin{array}{c}\text { Simpangan } \\
\text { Baku }(\mathrm{cm})\end{array}$ \\
\hline Laki-laki & 56 & $29,1-40,8$ & 33,696 & 2,4261 \\
Perempuan & 38 & $28,1-37,5$ & 33,145 & 2,6688 \\
Keseluruhan & 94 & $28,1-40,8$ & 33,473 & 2,5276 \\
\hline
\end{tabular}

Tabel 5. Panjang femur kanan dan kiri subjek penelitian 


\begin{tabular}{l|l|l|l|l}
\hline $\begin{array}{l}\text { Jenis } \\
\text { Kelamin }\end{array}$ & Jumlah & $\begin{array}{l}\text { Panjang } \\
\text { Femur }(\mathrm{cm})\end{array}$ & Rata-rata & $\begin{array}{l}\text { Simpangan } \\
\text { Baku }(\mathrm{cm})\end{array}$ \\
\hline Laki-Laki & 56 & $29,1-41,0$ & 33,703 & 2,4194 \\
Perempuan & 38 & $28,1-37,5$ & 33,155 & 2,6598 \\
Keseluruhan & 94 & $28,1-41,0$ & 33,481 & 2,5268 \\
\hline
\end{tabular}

Tabel 6. Korelasi Panjang badan dengan panjang femur kanan

\begin{tabular}{c|c|c|c}
\hline Jenis Kelamin & Jumlah & Korelasi Pearson (r) & $\mathrm{P}$ \\
\hline Laki-laki & 56 & 0,658 & $\mathrm{P}<0,01$ \\
Perempuan & 38 & 0,650 & $\mathrm{P}<0,01$ \\
Keseluruhan & 94 & 0,537 & $\mathrm{P}<0,01$ \\
\hline
\end{tabular}

Tabel 7. Korelasi Panjang badan dengan panjang femur kiri

\begin{tabular}{c|c|c|c}
\hline Jenis Kelamin & Jumlah & Korelasi Pearson (r) & $\mathrm{P}$ \\
\hline Laki-laki & 56 & 0,659 & $\mathrm{P}<0,01$ \\
Perempuan & 38 & 0,653 & $\mathrm{P}<0,01$ \\
Keseluruhan & 94 & 0,540 & $\mathrm{P}<0,01$ \\
\hline
\end{tabular}

Tabel 8. Korelasi panjang badan dengan panjang femur kanan dan kiri

\begin{tabular}{l|l|l|l}
\hline Jenis Kelamin & Jumlah & Korelasi Pearson (r) & $\mathrm{P}$ \\
\hline Laki-laki & 56 & 0,658 & $\mathrm{P}<0,01$ \\
Perempuan & 38 & 0,650 & $\mathrm{P}<0,01$ \\
Keseluruhan & 94 & 0,537 & $\mathrm{P}<0,01$ \\
\hline
\end{tabular}

\section{PEMBAHASAN}

Pada penelitian ini yang menjadi sampel penelitian adalah etnis Madidir Ure yang berusia 21-55 tahun dengan pertimbangan bahwa pertumbuhan tulang terhenti sekitar usia 18-20 yang berarti pada usia 21 tahun tidak ada pertumbuhan tulang lagi. Subjek penelitian berjumlah 94 orang yang terdiri dari 56 orang laki-laki dan 38 orang perempuan. 
Pada tabel I penelitian diperoleh subjek penelitian dimana laki-laki berumur antara 25-54 tahun dengan rata-rata 41,16 \pm 6,830 tahun dan subjek penelitian perempuan berumur antara 23-55 tahun dengan rata-rata 38,82 $\pm 8,589$ tahun. Secara keseluruhan subjek penelitian berumur antara 23-55 tahun dengan rata-rata 40,21 \pm 7,634 tahun.

Pada tabel 2 penelitian diperoleh panjang badan subjek penelitian laki-laki antara 136,5-179,0 cm dengan rata-rata $163,302 \pm 6,4351 \mathrm{~cm}$ dan pada subjek penelitian perempuan antara 138,5-164,5 cm dengan rata-rata $151,076 \pm 5,8313 \mathrm{~cm}$. Secara keseluruhan panjang badan subjek penelitian adalah 136,5-179,0 cm dengan rata-rata $158,360 \pm 8,6256 \mathrm{~cm}$. Jadi dapat dilihat adanya perbedaan 12,226 cm antara panjang badan subjek penelitian laki-laki dan perempuan.

Pada tabel 3 dapat dilihat bahwa terdapat perbedaan antara panjang femur kanan subjek penelitian laki-laki dengan panjang femur subjek penelitian perempuan. Dimana panjang femur kanan subjek penelitian laki-laki berkisar antara 29,1-41,0 cm dengan rata-rata 33,709 $\pm 2,4347 \mathrm{~cm}$, sedangkan panjang femur kanan subjek penelitian perempuan berkisar antara 28,1$37,5 \mathrm{~cm}$ dengan rata-rata 33,166 $\pm 2,6866$ $\mathrm{cm}$. jadi terdapat perbedaan walaupun hanya kecil perbedaan yang ditunjukan yaitu 0,54 $\mathrm{cm}$.

Pada tabel 4 dapat dilihat pula terdapat perbedaan pada panjang femur kiri. Dimana, panjang femur kiri subjek penelitian laki-laki berkisar antara 29,1-40,8 $\mathrm{cm}$ dengan rata-rata 33,696 $\pm 2,4261 \mathrm{~cm}$ sedangkan panjang femur subjek penelitian perempuan berkisar antara 28,1-37,5 cm dengan rata-rata 33,145 $\pm 2,6688 \mathrm{~cm}$. dengan demikian terdapat perbedaan pula pada panjang femur kiri walaupun hanya kecil pada subjek penelitian laki-laki dan perempuan yaitu $0,53 \mathrm{~cm}$.

Pada tabel 5 dapat dilihat secara keseluruhan panjang femur kanan dan kiri. Pada subjek penelitian laki-laki panjang femur keseluruhan berkisar antara 29,1-41,0 cm dengan rata-rata 33,703 $\pm 2,4194 \mathrm{~cm}$ dan pada subjek penelitian perempuan panjang femur keseluruhan berkisar antara 28,1-37,5 $\mathrm{cm}$ dengan rata-rata 33,155 $\pm 2,6598 \mathrm{~cm}$. Secara keseluruhan panjang femur berkisar antara 28,1-41,0 cm dengan rata-rata 33,481 $\pm 2,5268 \mathrm{~cm}$.

Hasil penelitian panjang badan pada tabel 2 (panjang badan subjek penelitian) jika dihubungkan dengan tabel 3,4,5(panjang tulang femur subjek penelitian) diperoleh suatu perbandingan yang berbanding lurus antara panjang badan dengan panjang tulang femur. Artinya semakin besar panjang femur maka semakin besar pula panjang badan.

Semua data yang terkumpul dilakukan analisis regresi antara panjang badan dengan panjang femur baik kanan maupun kiri, pada laki-laki dan perempuan serta keseluruhan subjek penelitian, dengan menggunakan rumus analisis regresi linier sederhana:

$$
\mathrm{Y}=\mathrm{a}+\mathrm{bX}
$$

Dimana :

$\mathrm{Y}=$ Variabel terikat, dalam hal ini adalah panjang badan

$\mathrm{a}=$ Konstanta

$\mathrm{b}=$ Koefisien regresi

$\mathrm{X}=$ Variabel bebas, dalam hal ini adalah panjang femur

Maka didapatkan pada subjek penelitian secara keseluruhan untuk panjang femur kanan dan kiri nilai koefisien korelasi (r) yaitu 0,537.Pada subjek penelitian lailaki diperoleh nilai koefisien korelasi (r) 
yaitu 0,658.Pada subjek penelitian perempuan diperoleh nilai koefisien korelasi (r) yaitu 0,650.Dari hasil analisis diperoleh suatu korelasi yang kuat antara panjang badan dengan panjang tulang femur.

Melalui analisis regresi didapatkan rumus persamaan untuk memperkirakan panjang badan dengan panjang tulang femur.

a. Untuk subjek penelitian laki-laki didapatkan persamaan

Panjang badan $=104,662+1,740 \mathrm{x}$ panjang femur

b. Untuk subjek penelitian perempuan didapatkan persamaan

Panjang badan $=104,298+1,410 \mathrm{x}$ panjang femur

c. Untuk keseluruhan subjek penelitian didapatkan persamaan

Panjang badan $=97,265+1,824 \mathrm{x}$ panjang femur

Dengan persamaan diatas, maka dapat dikatakan pada subjek penelitian laki-laki panjang badan akan bertambah sebesar 1,740 cm bila panjang femur ratarata bertambah $1 \mathrm{~cm}$. Pada subjek penelitian perempuan panjang badan akan bertambah sebesar $1,410 \mathrm{~cm}$ bila panjang femur rata-rata bertambah $1 \mathrm{~cm}$. Dan secara keseluruhan, panjang badan akan bertambah 1,824 cm bila panjang femur rata-rata bertambah $1 \mathrm{~cm}$.

Secara keseluruhan, pada penelitian ini didapatkan hubungan antara panjang badan dengan panjang tulang femur dan rumus regresi linier yang dihasilkan dapat digunakan untuk menentukan panjang badan seseorang berdasarkan panjang tulang femur.

\section{KESIMPULAN}

1. Terdapat hubungan antara panjang badan dengan panjang tulang femur pada etnis Sangihe di Madidir
Uredan panjang badan dapat

ditentukan berdasarkan panjang tulang femur.

\section{SARAN}

1. Perlu dilakukan penelitian lebih lanjut pada suku atau etnis yang lain yang belum pernah dilakukan agar dapat diketahui variasi panjang badan berdasarkan suku atau etnis yang lainnya.

\section{DAFTAR PUSTAKA}

1. Snell RS. Anatomiklinikuntukmahasiswakedok teranedisi 6.Jakarta: EGC. 2006; hal. 2.

2. Manik MI. Hubungantinggibadandenganpanjang tulang tibia mahasiswaFakultasKedokteranUnsra tangkatan 2010. Unpublished. Manado. 2012; hal.1.

3. Devision RJ. Penentuantinggibadanberdasarkanpa njanglenganbawa. Medan. 2009; hal.1-3.

4. Badan Penelitian Dan Pengembangan Kesehatan Departemesn Kesehatan RI. Pedoman Pengukuran Dan Pemeriksaan. Jakarta. 2007 [cited 2013 Sep 22]. Available from :http://www.riskesdas.litbang.depkes.go. id/download/PedomanPengukuran.pdf.

5. University of Oxford. Simple Linear Regression. Oxford University Press. [cited 2014 Feb 28] Available from : www.oxfordjournals.org/tropej/ online/ma_chap2.pdf 
